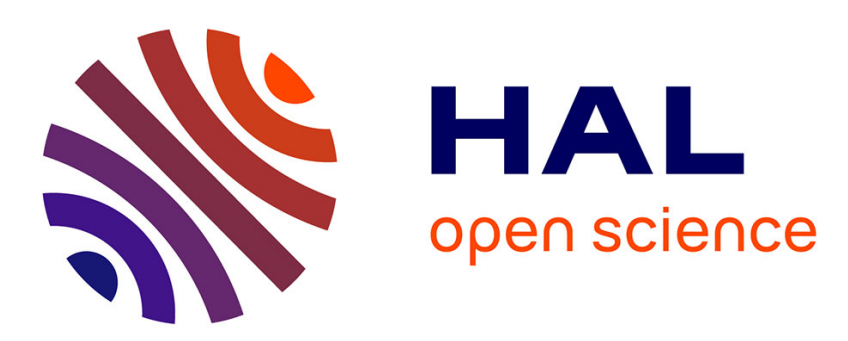

\title{
Energy Consumption Optimization through Dynamic Simulations for an Intelligent Energy Management of a BIPV Building
}

\author{
Ilias Papas, Bruno Estibals, Christelle Ecrepont, Corinne Alonso
}

\section{- To cite this version:}

Ilias Papas, Bruno Estibals, Christelle Ecrepont, Corinne Alonso. Energy Consumption Optimization through Dynamic Simulations for an Intelligent Energy Management of a BIPV Building. 7th International Conference on Renewable Energy Research and Applications, IEEE, Oct 2018, Paris, France. 10.1109/ICRERA.2018.8566915 . hal-01963514

\author{
HAL Id: hal-01963514 \\ https://hal.laas.fr/hal-01963514
}

Submitted on 26 Dec 2018

HAL is a multi-disciplinary open access archive for the deposit and dissemination of scientific research documents, whether they are published or not. The documents may come from teaching and research institutions in France or abroad, or from public or private research centers.
L'archive ouverte pluridisciplinaire HAL, est destinée au dépôt et à la diffusion de documents scientifiques de niveau recherche, publiés ou non, émanant des établissements d'enseignement et de recherche français ou étrangers, des laboratoires publics ou privés. 


\title{
Energy Consumption Optimization through Dynamic Simulations for an Intelligent Energy Management of a BIPV Building
}

\author{
Ilias Papas, Bruno Estibals, Christelle Ecrepont, Corinne Alonso \\ Integration of Energy Management Systems \\ LAAS-CNRS \\ Toulouse, France \\ ipapas@laas.fr
}

\begin{abstract}
Having 6500 integrated sensors and a wide network of embedded systems, the ADREAM building can be categorized as one of the prototype smart buildings of France. As needs for intelligent management of energy are growing, the associated project provides a multidisciplinary platform of experimentation, developing solutions for efficient Energy Networks, HVAC Systems, Photovoltaics, and Smart Grids. This paper provides the overview of the project along with three different modeling techniques, illustrating their strengths and limitations on simulating the thermal behavior of the building and the functioning of the different energy systems. A thermal model of the building was developed and calibrated for energy consumption analysis and prediction, using the software Pleiades+Comfie. A "black box" model was developed using artificial neural networks for the simulation of energy system parameters and the exploration of efficient control strategies. The last method provides the overview of developing an allinclusive electrically equivalent physical model with Matlab/Simulink for simulating the global functioning of the building and its HVAC systems. The conclusion addresses the utility of exploring and combining different types of models for optimizing the energy management of Smart Buildings.
\end{abstract}

Keywords - Smart Building, Building Simulation, Energy Management, Energy Optimization, Pleiades + Comfie, Model Calibration, Simulink

\section{INTRODUCTION}

Energy management optimization is a growing issue in our society. As buildings account for about $40 \%$ of the global energy consumption, the EU proposes a target of $27 \%$ more energy savings by 2030 [1]. The global initiative for energy optimization gave rise to the concept of Zero Energy Buildings (ZEB), which was first defined in scientific literature in 2006, but it had not been translated concretely into laws and norms. After the National Renewable Energy Laboratory (NREL) proposed an initial definition, Aalborg University produced a state of the art synthesis of ZEB definitions [2] [3]. Thus, the research focused on demonstrations over one-year-cycles, which eventually highlighted the fact that energy demand for heating and electrical consumption needs to be minimized. At the same time, the energy supply should rely completely on a building's annual production of renewable energy [4] [5]. The most common source exploited for energy production is solar energy. The development of buildings that aim to minimize consumption while maximizing production of energy, such as the ADREAM building, promoted the spread of Building Integrated Photovoltaic (BIPV) systems.

The constantly increasing focus of the scientific community on the optimization of BIPV Systems can be demonstrated in [21], [22], [23], [24], while the interest for Building Energy Management Optimization can be seen in [25].

Therefore, the ADREAM project, combining ideas from optimized designs of other sustainable buildings, such as the Solaris project in the Paris region [8], and the Edge in Amsterdam [9], aims to stand as one of the world's prototype models for intelligent energy management. This paper presents the scientific context of the ADREAM building in Section II. The description and analysis of the various modeling strategies that aim to predict and optimize thermal and electrical consumption is given in Sections III, IV, and V. Section VI provides the evaluation of the associated results and concludes on the ongoing research, while it outlines the future work in the domains of thermal and electrical energy consumption optimization.

\section{SCIENTIFIC CONTEXT OF THE ADREAM BUILDING}

The ADREAM project (French acronym for Embedded Reconfigurable Dynamic Autonomous and Mobile Architectures) is a research program focused on the optimization of Smart Grids, Micro-Grids, BIPV systems, HVAC (Heating, Ventilation, Air Conditioning) systems, as well as on Ambient Physical Cyber Systems [10]. Figure 1 shows an aerial view of the building along with its large PV surface. Figure 2 illustrates the various Energy Systems installed in the building.

This paper focuses on ADREAM's objective of developing a modeling approach to energy management and optimization for the totality of the installed systems, integrating all the entities of production and consumption, by deploying the extensive network of intelligent sensors and regulators. The presented work provides an overview of three different modeling and simulation methods whose aim is to explore applicable solutions for the energy consumption optimization objective of ADREAM through an intelligent management of 


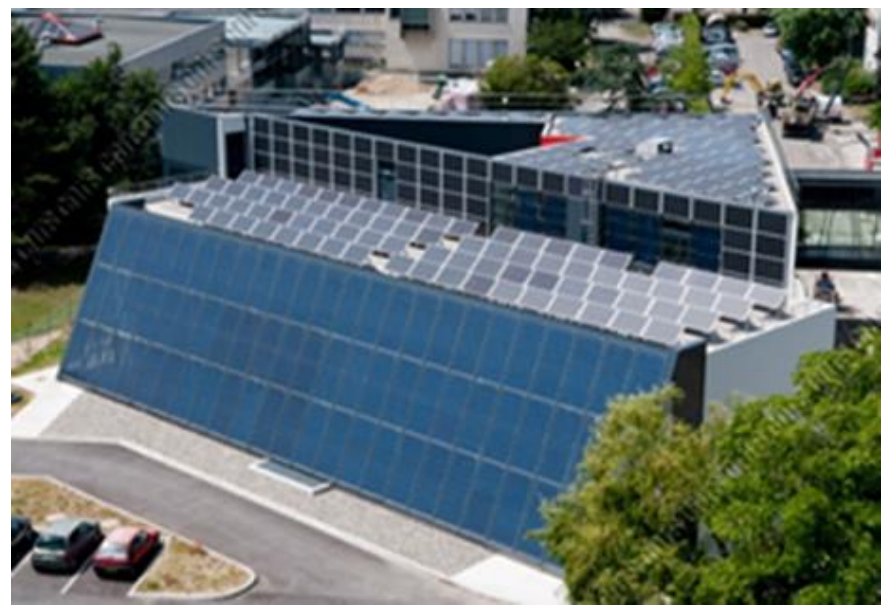

Fig. 1. Aerial view of the ADREAM Building

energy. Thus, for this purpose, the modeling process incorporates and explores the interaction of the thermal and electrical elements in the building. Similar work focusing on the modeling process and optimization of HVAC systems and energy consumption can be found in [26], [27], [28], [29], and [30].

This study concerns the transfer of energy within the ADREAM building considering the heating, the air conditioning, the lighting, and the various electronic devices. ADREAM is connected to an electrical grid which benefits from a total of $100 \mathrm{kWc}$ of photovoltaic energy. In addition, it involves the use of geothermal energy through the installation of three ground source heat pumps $(135 \mathrm{~kW})$. The hygienic ventilation system is also linked to a ground heat exchanger to minimize the heating/cooling energy needs of the air. The notion of a ZEB is examined extensively through the ADREAM research program as the electrical energy surplus from the photovoltaic production, combined with the optimized consumption of high performance HVAC (Heating, Ventilation, and Air Conditioning) systems, can be transported to the rest of the buildings composing the LAAS-CNRS laboratory. The principal objective of the ADREAM project is to give rise to a building of optimized energy consumption and production, while achieving periodical states of positive energy, without compromising user comfort. Figure 2 shows the interconnection of the various energy systems installed in the building. The specific details of the ADREAM Energy Network, the Database Supervision and Control System are given in Papas et al. [14].

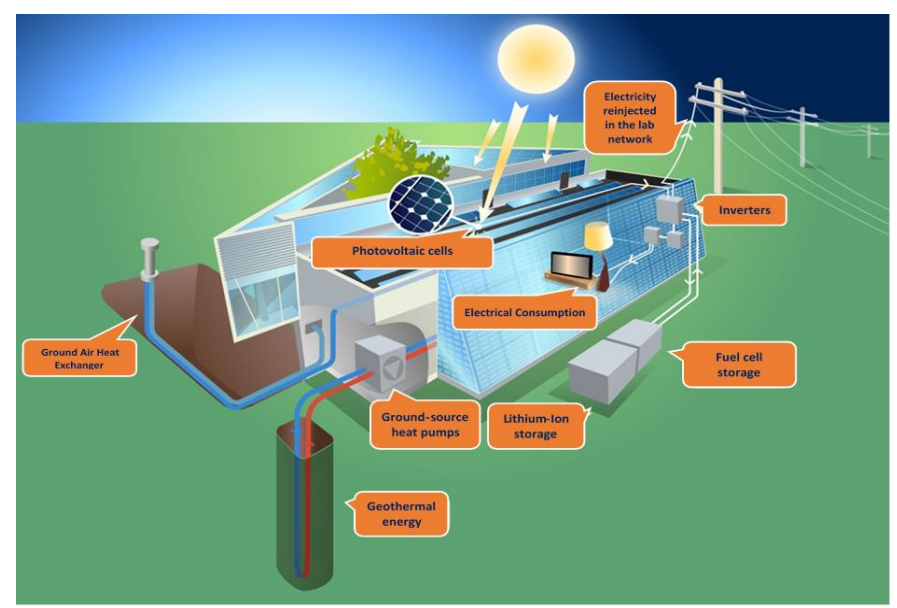

Fig. 2. Energy Systems installed in the ADREAM Building

\section{DYNAMIC THERMAL SIMULATION}

The initial modeling phase of the building ADREAM was carried out by the software Pleiades + Comfie $(\mathrm{P}+\mathrm{C})$ [12]. $\mathrm{P}+\mathrm{C}$ is a widely used thermal simulation program developed at the Ecole des Mines in Paris and supplied by the company Izuba. As indicated by Peuportier [13], $\mathrm{P}+\mathrm{C}$ can be considered as a precise simulation tool for the generation of temperature evolution and energy needs profiles, as well as for the study of their sensibility to main thermal parameters.

A Dynamic Thermal Simulation (DTS) serves as a computer tool that allows the thermal study and electrical energy assessment of a building from multiple perspectives (temperature profiles, energy consumption, comfort). The interest for this type of modeling stems from the motivation to simulate with high precision the particular architecture of ADREAM's structure, along with its thermal properties and the technical characteristics of the systems installed for the purpose of optimizing its thermal and electrical energy consumption. The complete procedure of this modeling algorithm and method is described in Papas et al. [14]. Figure 3 shows the 3D Model of the ADREAM Building in the software interface.

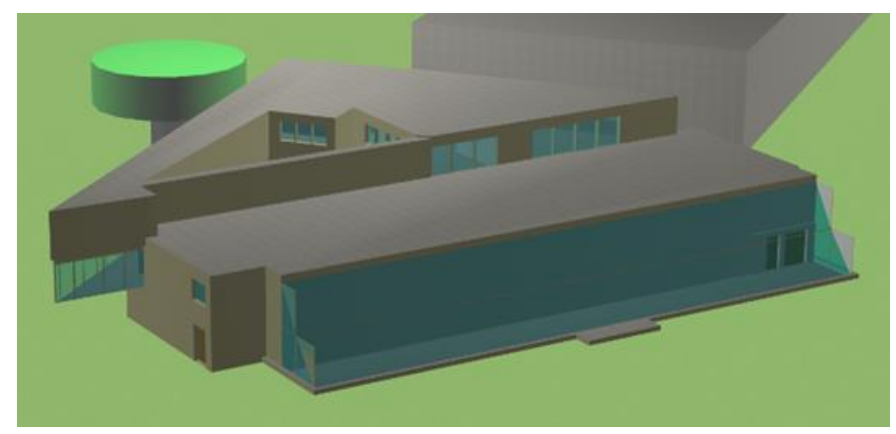

Fig. 3. 3D Model of the ADREAM Building

The $\mathrm{P}+\mathrm{C}$ model was calibrated after a series of validated estimations and hypotheses, which were based on in situ measurements, sensor data, and information extracted from a survey to the ADREAM's occupants. Table 1 shows the evolution of the statistical indicators (NMBE (Normalized Mean Bias Error) and CVRMSE (Coefficient of Variation of Root Mean Square Error)) from the initial to the final simulation, while Figure 4 illustrates the fit between measured data ( $\mathrm{T}$ REAL) and simulated data ( $\mathrm{T}$ INITIAL SIMULATION) and ( $T$ FINAL SIMULATION) for the evolution of the interior temperature of an office [14].

TABLE 1: Statistical indicators for the initial and final simulations

\begin{tabular}{|c|c|c|}
\hline $\begin{array}{c}\text { Statistical } \\
\text { Indicator }\end{array}$ & $\mathrm{T}^{\circ}$ INITIAL SIMULATION & $\mathrm{T}^{\circ}$ FINAL SIMULATION \\
\hline NMBE & $4.57 \%$ & $0.48 \%$ \\
\hline $\mathrm{CV}$ (RMSE) & $5.51 \%$ & $2.84 \%$ \\
\hline
\end{tabular}




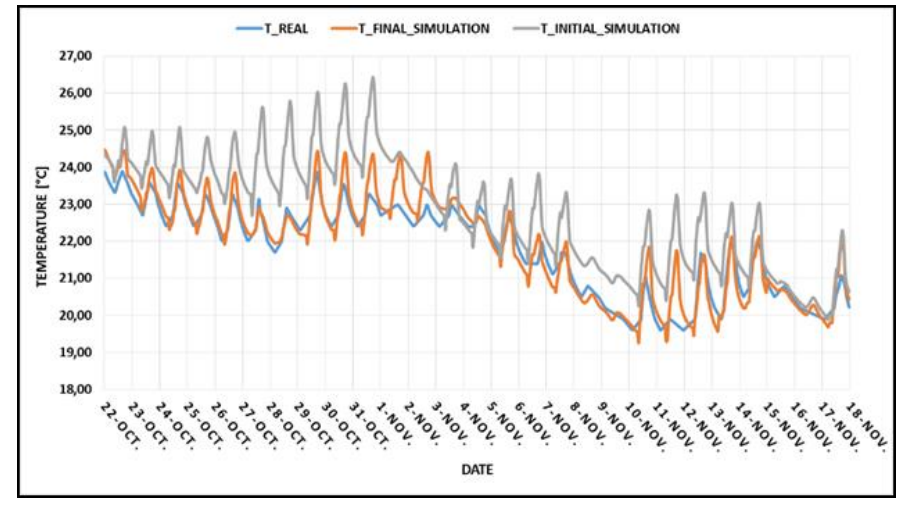

Fig. 4. Example of model calibration for an office during a 1-month period

The final step for carrying out a complete simulation including the building's thermal behavior analysis, as well as its electrical consumptions, involved the entry of all the HVAC systems' parameters. That is, in order to launch a complete simulation the required information concerned all the technical parameters of: a) the three heat pumps, b) the central AHU and the five individual AHU's, c) the ceiling fan coils, and d) the radiators. As shown by Papas et al [14], several strategies for reducing the energy consumption of ADREAM were evaluated with the potential of reducing the total electrical energy consumption by $20 \%$. Most notably, after the validation of the complete model, performing a parametric variation on the functioning parameters of the building's water distribution system produced very promising results for the total electrical consumption. Consequently, by replacing the constant flow circulation pumps with variable flow ones the building's energy gain was close to or superior to the simulated gain, as shown in Table 2.

TABLE 2: Comparison of the building's electrical consumption between 2014 and $2017+2018$ following the implementation of optimization strategies

\begin{tabular}{|c|c|c|}
\hline & $\begin{array}{c}\text { HVAC } \\
\text { Consumption } \\
2014 \text { [MWh] }\end{array}$ & $\begin{array}{c}\text { HVAC } \\
\text { Consumption } \\
2017 \text { [MWh] }\end{array}$ \\
\hline \multirow{3}{*}{$\begin{array}{l}\text { Jan.-Mai + Sep.- } \\
\text { Dec. }\end{array}$} & 83,61 & 70,57 \\
\hline & Energy Gain & $16 \%$ \\
\hline & $\begin{array}{c}\text { HVAC } \\
\text { Consumption } \\
2014 \text { [MWh] }\end{array}$ & $\begin{array}{c}\text { HVAC } \\
\text { Consumption } \\
2018 \text { [MWh] }\end{array}$ \\
\hline \multirow[t]{2}{*}{ Jan. - June } & 44,87 & 34,669 \\
\hline & Energy Gain & $23 \%$ \\
\hline
\end{tabular}

\section{Black Box Modeling With ARTIFICIAL NEURAL NETWORKS}

For very complex systems and interactions, such as the ones corresponding to the building ADREAM, it is often useful to use a "Black Box" modeling method through the exploitation of Artificial Neural Networks (ANN) [17]. The "Black Box" process approximates the physical equations governing the interaction of energetic systems by applying linear differential equations which associate a specific output to a finite number of past inputs and outputs [14]. In the case of the ADREAM building, the modeling of the HVAC systems was pursued for the purpose of their performance optimization and their overall regulation. For the modeling of the heat pumps the input values used were the Electrical Power of the Heat Pumps, and the Return Water Temperature, while the output used was the Produced Water Temperature. The purpose behind the use of these variables has to do with the fact that they all depend on each other. At the same time, by studying the evolution of the water temperature, the estimation of the total electrical power consumption can be deduced and consequently predicted.

A dynamic non-linear filtering was implemented for the prediction of the return water temperature based on its past outputs and on the produced water temperature inputs. The method used is that of the Non-Linear Autoregressive Model with External Inputs (NARX), where an output $y(t)$ is predicted for a given $d$ amount of past $y(t)$ and $x(t)$ values. Equation 1 represents the NARX model applied.

$$
\begin{array}{r}
y(t)=f(x(t-1), \ldots, x(t-d), \\
y(t-1), \ldots, y(t-d))
\end{array}
$$

Where:

$\mathrm{y}(\mathrm{t})=$ Return Water Temperature $\left[{ }^{\circ} \mathrm{C}\right]$

$\mathrm{x}(\mathrm{t})=$ Produced Water Temperature $\left[{ }^{\circ} \mathrm{C}\right]$

$\mathrm{d}=$ Sample data

As it can be observed in Figures 4 and 5, the fit between model and measured data falls into an accepted level. The two figures compare the ANN model output with the measured data for the produced water and return temperature of the heat pumps. The statistical indicators corresponding to this correlation are, for Figure 4: NMBE $=0.23 \%$ and CV(RMSE) $=1.93 \%$, and for Figure 5 : NMBE $=-0.62 \%$ and $\mathrm{CV}(\mathrm{RMSE})=$ $1.90 \%$. The development of such a precise model is due to the fact that the algorithm is improved through the "feeding" of the past outputs during the training of the network [20].

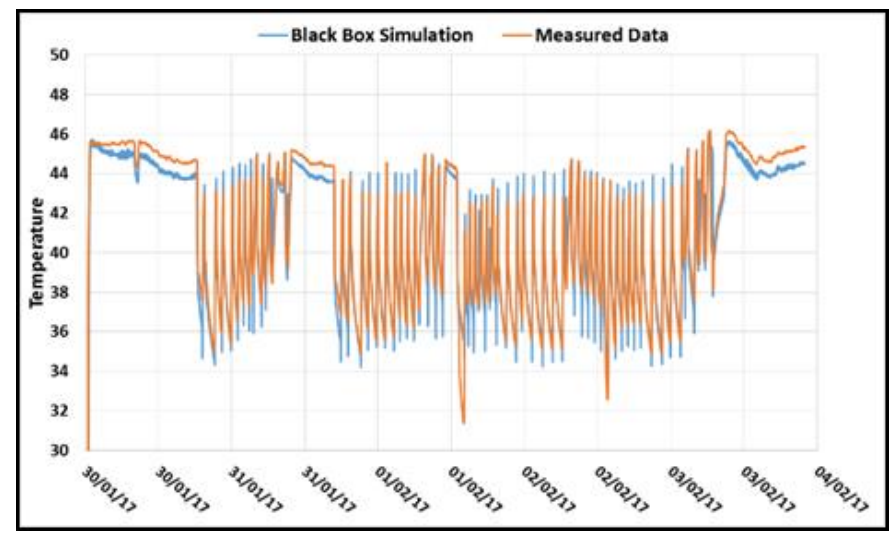

Fig. 5. Produced water temperature $\left[{ }^{\circ} \mathrm{C}\right]$

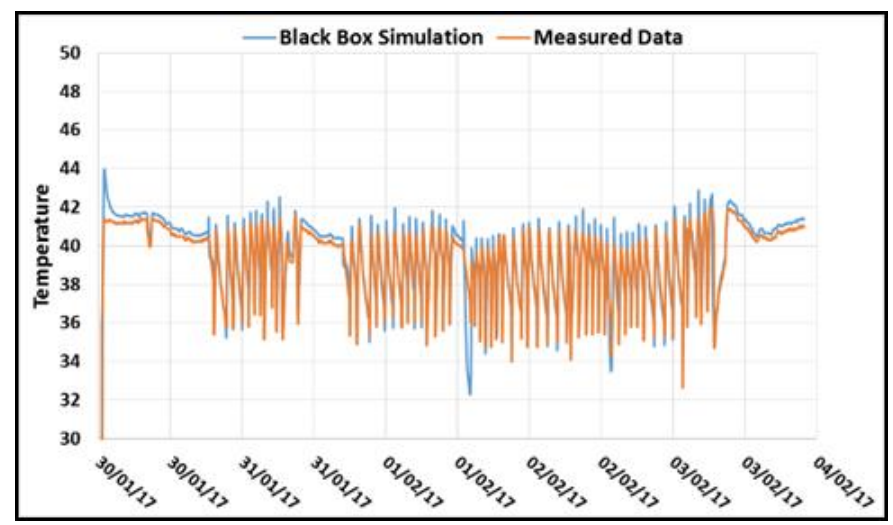

Fig. 6. Return Water Temperature $\left[{ }^{\circ} \mathrm{C}\right]$ 
Since the purpose of this study is the development of a global model that has the ability to predict power consumption through valid simulated data, independent of the registered data, it is essential to produce the input of the return temperature through a model. Thus, a global model combining ANN and physical elements was developed with Simulink for the purpose of simulating the interaction of all the systems with each other and with the building. However, simulating the interaction between ANN and physical elements has an impact on the robustness of the ANN models. For this reason, a more robust physical model comprising the totality of the systems and the buildings was explored.

\section{PHYSICAL MODELING IN SIMULINK}

The complete physical model of the ADREAM building, along with all the HVAC systems installed is developed through the use of Matlab and the Simulink interface. Exploring this methodology allows the detailed mathematical description of each physical entity and system through a model which can simulate their interaction. At the same time, the simulation outputs are equivalent to those of an electrical network model such as an energy production network or an electrical storage network.

For the development of the Simulink model, the physical equations of the HVAC systems were either manually entered or modeled through physical and thermal elements of the Simscape library. The main model components involved the Heat Pumps System, the Geothermal System, the Water Storage, the Fan Coils, and the Building. Figure 7 shows the complete model of the ADREAM Building and its interaction with the Heat Pump, the Geothermal System, and the Water Storage Units. Simulating the energy needs of the building according to its temperature set-points for a given period, the model can produce the thermal energy consumed. Knowing the value of the Heat Pumps' Coefficient of Performance (COP) for each season, allows the calculation of the total electrical consumption.

\section{CONCLUSION}

This paper explored three different modeling methodologies for the optimization of the thermal and electrical consumption of the ADREAM building. The first method involved the calibration of a Dynamic Thermal Simulation for the purpose of analyzing the thermal behavior of the building and reducing its electrical consumption. The second one consisted of the "Black Box" modeling method through the exploitation of Artificial Neural Networks (ANN) with the objective of exploring optimized control strategies. The third method presented a global model developed in Simulink incorporating all systems of consumption in interaction with the building. All modeling methodologies proved to be very precise tools according to the calculation of statistical indicators, such as the RRMSE and NMBE. However, for the purpose of advancing further the objectives of the ADREAM project to be part of the ZEB research community, the last model will be explored more thoroughly in combination with electrical network models for the development of an efficient strategy involving energy production, consumption, and storage. The final aim of this project involves the exploration of more efficient control strategies for the optimization of the thermal and electrical energy consumption through an intelligent management of energy, providing a prototype model which can serve as an example for the regulation and controls strategies of a sustainable building.

\section{ACKNOWLEDGMENT}

This project has been financed by the University of Toulouse III - Paul Sabatier in collaboration with the research association Neocampus.

Fig. 7. Global Model of Building + HVAC Systems in Simulink

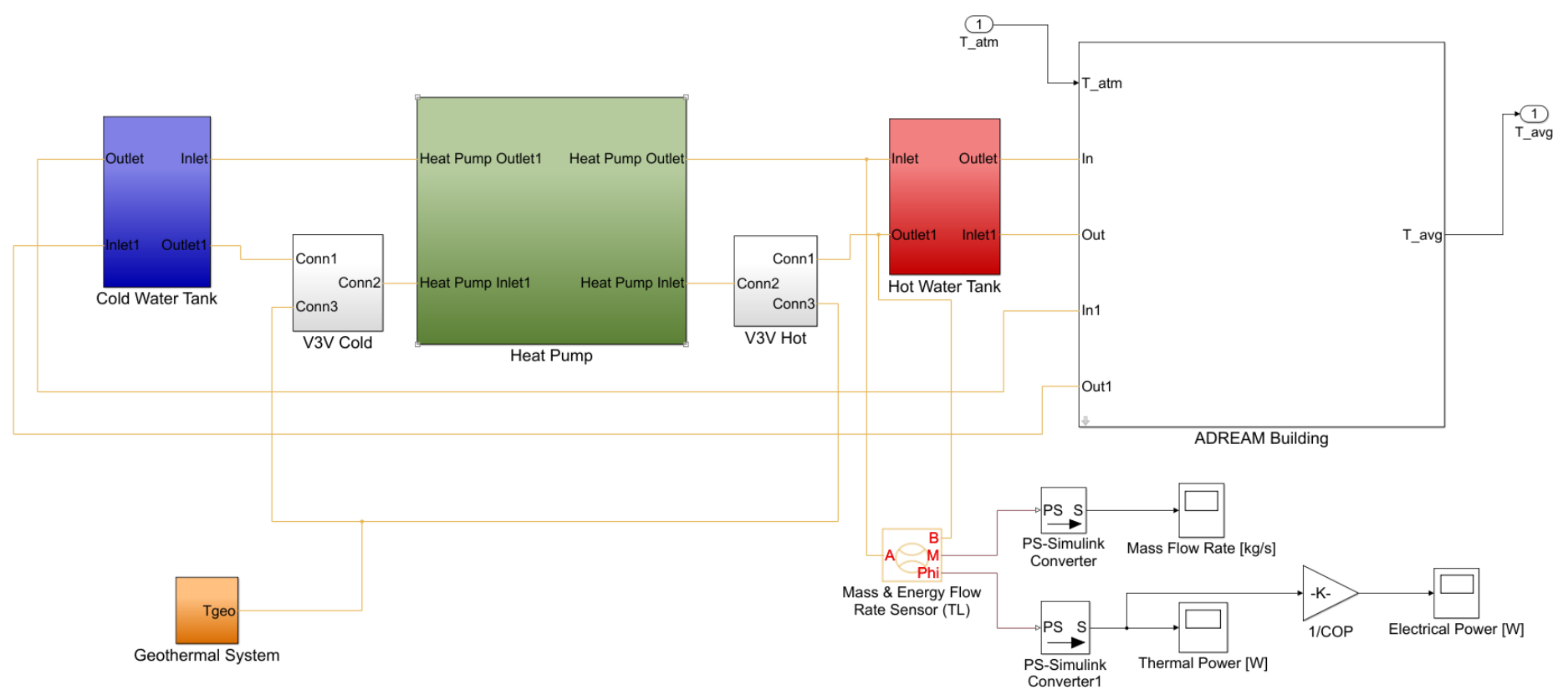




\section{REFERENCES}

[1] http://ec.europa.eu/energy/en/topics/energy-strategy/2030-energy-strategy (accessed 21.01.2017)

[2] P. Torcellini, S. Pless, and M. Deru, D. Crawley, "Zero Energy Buildings: A Critical Look at the Definition”. Preprint NREL ACEEE Summer Study Pacific Grove, California August 14-18, 2006.

[3] Anna Joanna Marszal, Per Heiselberg « A literature review of Zero Energy Building (ZEB) definitions ». December 2009@ Aalborg University. ISSN 1901-726X. DCE Technical Report No. 78.

[4] A.J. Marszal, P. Heiselberg, J. S. Bourrelle, E. Musall, K. Voss, A Napolitano. «Zero Energy Building - A review of definitions and calculation methodologies » Energy and Building (2011)

[5] L Wang, J Gwilliam, P Jones, "Case study of zero energy house design in UK", Energy and buildings 41 (2009) 1215-1222

[6] Isa, N. B. M., Wei, T. C., \& Yatim, A. H. M., Smart grid technology: Communications, power electronics and control system, Sustainable Energy Engineering and Application, International Conference (2015) 10-14.

[7] Mohamed, M. A., Eltamaly, A. M., Farh, H. M., \& Alolah, A. I., Energy management and renewable energy integration in smart grid system. Smart Energy Grid Engineering (SEGE), 2015 IEEE International Conference (2015) pp. 1-6

[8] Solaris Positive Energy, Solaris Concept: The first reproducible green office building with positive energy, (2012) < http://www.solaris-energiepositive.com/solaris-positive-energy-saving-positive-energy-building.php>.

[9] Randall, T., The Smartest Building in the World: Inside the Connected Future of Architecture, (2015) <http://www.bloomberg.com/features/2015-the-edgethe-worlds-greenest-building/>

[10] https://www.laas.fr/public/en/adream.

[11] PCVue Solutions, <http://www.pcvuesolutions.com>.

[12] Izuba Energies, Pleiades+Comfie, 〈http://www.izuba.fr/logiciel/comfie>.

[13] B. Peuportier, Bancs d'essais de logiciels de simulation thermique, Journée Thématique SFT-IBPSA (2005).

[14] I. Papas, C. García Rodríguez, B. Estibals; C. Ecrepont, C. Alonso, "ADREAM:Energy Consumption Optimisation through Dynamic Energetic Simulations for an Intelligent Management of Energy", 2016 Intl IEEE Conferences on Ubiquitous Intelligence \& Computing, Advanced and Trusted Computing, Scalable Computing and Communications, Cloud and Big Data Computing, Internet of People, and Smart World Congress, p 975 983.

[15] ASHRAE, ASHRAE Guideline 14-2002, Measurement of Energy and Demand Savings, ASHRAE, Atlanta, 2002
[16] A.T. Nguyen, S. Reiter, An investigation on thermal performance of a low cost apartment in hot humid climate of Danang, Energy and Buildings 47 (2012) 237-246

[17] System Identification Toolbox - ARX Models. <http://www.rohan.sdsu.edu/doc/matlab/toolbox/ident/ch2gui20.html>

18] T. Salque, D. Marchio, "Development of a Neural Network-based Building Model and Application to Geothermal Heat Pumps Predictive Control", SIMUL 2012: The Fourth International Conference on Advances in System Simulation (2012) 24-29.

[19] G. Xu, A. Kusiak, "Modeling and optimization of HVAC systems using a dynamic neural network", Energy 42 (2012) 241-250.

[20] https://fr.mathworks.com/help/nnet/ug/design-time-series-narx-feedbackneural-networks.html.

[21] S. Kirmani, et al., "Effective low cost Grid-Connected Solar Photovoltaic System to Electrify the Small Scale industry/Commercial Building", International Journal of Renewable Energy Research, Vol. 7, No 2, 2017.

[22] M. Elloumi, at al., "Multi Agent System Design for PV Integrated Home Management", International Journal of Renewable Energy Research, Vol. 8, No 1, 2018

[23] A. Kane, et al., "Performance Enhancement of Building Integrated Photovoltaic Module using Thermoelectric Cooling", International Journal of Renewable Energy Research, Vol. 3, No 2, 2013.

[24] E. Tarigan, "Simulation and Feasibility Studies ofRooftop PV System for University Campus Buildings in Surabaya, Indonesia”, International Journal of Renewable Energy Research, Vol. 8, No 2, 2018.

25] Abhinaya K.S. et al., "Assessment and Remodelling of a Conventional Building Into a Green Building Using BIM", International Journal of Renewable Energy Research, Vol. 7, No 4, 2017.

[26] J. De Leon-Ruiz, et al., "Mathematical Thermal Modelling of a DirectExpansion Solar-Assisted Heat Pump Using Multi-Objective Optimization Based on the Energy Demand”, Energies, 11, 1773, 2018

[27] S. Chokchai, et al., "A Pilot Study on Geothermal Heat Pump (GHP) Use for Cooling Operations, and on GHP Site Selection in Tropical Regions Based on a Case Study in Thailand", Energies, 11, 2356, 2018.

[28] W. El-Baz, et al., "Experimental Study and Modeling of Ground-Source Heat Pumps with Combi-Storage in Buildings", Energies, 11, 1174, 2018.

[29] A. Arteconi, et al., "Assessing the Demand Side Management Potential and the Energy Flexibility of Heat Pumps in Buildings", Energies, 11, 1846, 2018.

[30] S. Staub, et al., "Reversible Heat Pump-Organic Rankine Cycle Systems for the Storage of Renewable Electricity", Energies, 11, 1352, 2018. 